\title{
The Improvement Self-Regulation of Children Aged 5-6 Years Through Activities in a Mini Garden
}

\author{
Mia Rachmawaty ${ }^{1 *}$, Warid Warid ${ }^{2}$ \\ ${ }^{1}$ Early Childhood Education, Trilogi University, 12760, Jakarta, \\ ${ }^{2}$ Agroecotechnology, Trilogi University, 12760, Jakarta \\ *Email: mia_rachmawaty@trilogi.ac.id
}

\begin{abstract}
Children's self-regulation is built from environmental support. This research is motivated by the lack of teacher knowledge in designing smart pedagogy as a learning strategy. This affects the ability of selfregulation in children who are still low in daycare, this is known as preliminary information for researchers with the results of discussions with parents on daycare about the child's ability to control themselves and organize themselves in the scope of simple daily tasks. Then the researchers also obtained observations through documents that showed the teacher also did not design learning strategies that were good enough to improve the ability of self-regulation in the design of routine activities on the daily activity sheet. Even gardening is limited to playing in the yard and there are no specific learning goals. Some daycare centers make mini-gardens, but are not designed as daily programs that can be integrated with self-management skills. The stages of the implementation of the Mini Garden provide rules and allow children to explore and practice self-regulation. The function of Mini Garden is not only as a vacant lot in daycare. This study was designed on an action research model, which was created by testing Cycle 1 and Cycle 2 to find out whether the Mini Garden that has been created makes self-regulation in 30 children increase, the instrument used in this study is through observation and data checklist using self-indicators -regulation children aged 5-6 years. The indicators used are derived from the development of aspects of self-regulation, namely attention regulation, emotion regulation, and behavior regulation, which are used in the stages of mini garden activities and visualized through poster regulations for mini garden activities. The results showed that in the second cycle there was an increase in children's self-regulation ability to $84.3 \%$, which was previously only $42.9 \%$. Keywords: self-regulation, mini garden, early childhood
\end{abstract}

\section{INTRODUCTION}

The environment can have a large impact on a child's selfregulation. It is important to consider space for children. For example, is there anything in that space that can irritate or overwhelm a child, making it difficult for him to focus? Some children naturally become more agitated than others by certain experiences, and this affects the way they respond to their environment. Some children can become overly stimulated in new games with new people and may benefit from extra time for comfort. Some children may only tolerate one change or new element at a time. Other children need more stimulation to be alert enough to be responded to or asked for in certain discussions. For example, child-care activities that are different from activities in Early Childhood Education Institutions such as kindergarten. Because at the Daycare the children will more often meet new people, new friends, and ask them to be able to adapt and organize themselves according to and the environment and activities they face well. Preschoolers are starting to know how to play with other children and understand what is expected of them. As in life in daycare children are expected to be able to adapt and interact with daycare situations. In this case the ability of self-regulation is needed by children to be able to manage stress - because selfregulation helps children learn that he can cope with strong feelings and give him the ability to calm himself down after getting angry or in dealing with new tasks and environments.

High-quality Daycare shows that daycare with a complete service program can relieve parental stress [1]. Therefore, Daycare should be involved in smart pedagogy through stimulation activities that emphasize overall learning with the main focus on developing life skills and thinking skills. In this case, thinking skills are part of the area of selfregulation contained in an explanation of the "central cognitive element of self-regulation"[2], namely, there are three areas of self-regulation: metacognitive, metacognitive regulation and emotional regulation/motivation. Metacognitive knowledge refers to what people know about their cognition (individual knowledge about personal variables, task variables and strategy variables that affect their cognitive performance). In metacognitive regulation, which describes the metacognitive processes that occur during ongoing activities and involve four specifics regulatory behaviors: planning, monitoring, control, and 
evaluation. In the field of emotional regulation/motivation consists of monitoring or controlling emotions and motivational conditions during carrying out the tasks assigned.

Research states that self-regulation in children will increase with the support of parents for children's activities at school and attend training activities for parents held at school. The role of early childhood education (PAUD) must be pointed out in the research that states that parenting from a parent or Parent Training Only (PT) is not enough to increase selfregulation in children PAUD institutions (STP-Pre K/Prekindergarten) which are oriented to academics and the implementation of traditional curricula are considered sufficient to overcome child behavior, while PAUD institutions (STP-PreK Enhanced) which provide a multitarget and integrated approach for parents and children with parenting, skills programs academic and social-emotional development, can improve self-regulation and socialemotional skills in children [3]. In the graph explained that an early childhood education institution that only has training activities for parents in the School Readiness Parenting Program (SRPP) can improve the ability of selfregulation in children but the ability of children in the behavioral modification system and academic curriculum (STP-PreK) and not those having a program for additionally contained social - emotional and self-regulation training (STP-PreK Enhanced) also does not increase children's abilities, especially self-regulation. In contrast to the graph below which shows an increase in the ability of selfregulation in children in institutions that have treatment programs for pre-kindergarteners (STP-PreK) programs. One version included the standard behavioral modification system and academic curriculum (STP-PreK) while the other additionally contained social-emotional and selfregulation training (STP-PreK Enhanced). Experienced greater growth across time in academic achievement, emotion knowledge, emotion regulation, and executive functioning compared to children in the other groups. These findings suggest that while parent training is sufficient to address children's behavioral difficulties, an intensive summer program that goes beyond behavioral modification and academic preparation by targeting socio-emotional and self-regulation skills can have incremental benefits across multiple aspects of school readiness and collaboration with parents.

Research on the difference between working and nonworking mothers for better child development in nonworking mothers show that 12 children $(31.6 \%)$ have appropriate development and two children (5.3\%) have doubtful development. In working mothers, eight children (21\%) had appropriate development, 15 children $(39.5 \%)$ had doubtful development and one child (2.6\%) had deviant development [4]. For this reason, it can be concluded that working mothers need partners to care for and educate their children while they work so that the child's development can grow well and in accordance. Quality daycare is to have a program that supports child development by collaborating with parents.

Age 5-6 years is a preschool period where children will find a variety of behaviors and children will learn to distinguish between good behavior and bad behavior. Children often have difficulty using simple rules, and the ability to follow these rules will succeed and increase with age [5]. SelfRegulation is defined as monitoring and control over all aspects of human behavior, including emotional and motivational elements [6]. Stimulation of self-regulation in children is not only the responsibility of parents but in preschool where children enter early childhood education institutions (PAUD) is the role of teachers to dominate stimulation for children through daily behavioral habituation activities. Nowadays, many parents work outside the home and rely on Non-formal Early Childhood Education institutions such as daycare or childcare, as partners in the care and education of their children. So, selfregulation in children is guided and stimulated by educators and daycare caregivers during the child are entrusted with the daycare institution.

The Self-Regulation Questionnaire (SQR) explains the stages of self-regulation through seven phases, namely: receiving, evaluating, triggering, searching, formulating, implementing, assessing[7]. In children, there is an assessment for self-regulation aimed at three aspects, namely: attention regulation, emotion regulation, and behavior regulation[8]. Self-regulation on the need to prepare for kindergarten, namely: the ability to pay attention, control desires/impulses, participate in the gathering, play cooperatively and be able to follow instructions[9]. Self-regulation requires cognitive abilities and behaviors that in the process are influenced by basic factors, namely: the ability to remember, the ability to choose and sort out attention, the ability to suppress or withstand disturbances and the ability to monitor responses to success or failure[10]. Self-regulation on the use of technology influences children's grades and academic achievement in school. Research states that students who have high skills in self-regulation show the behavior to use fewer text messages during class and are more likely to maintain their attention to the ongoing learning process[11]. Technology is related to a person's ability to obtain certain results, solve problems, complete tasks, use skills, use knowledge and exploit assets[12]. Mini garden implementation, if planned well, will provide flexible and sweet learning opportunities for children and develop autonomy in their environment [13]. Mini Garden is a small park that will provide rewards not only for those who have limited space but limited time [14]. Mini garden is a small garden measuring a quarter of a hectare or less in a modern residential area[15]. The Mini Garden, which is included in the school garden, is defined as a park that is maintained as a learning environment to create meaningful experiences for students and is the most important part of school culture that is used continuously over time. The Ozer" is a garden preparation system as follows: 1) Garden logistics: planning (location determination), budgeting, maintenance, development and support organization circles, 2) Children's learning experience: curriculum, design time, type of activity, learning experience, learning development opportunities, 3) School Culture: organizational structure of the caretaker of the garden, involvement of parents, social 
activities of the harvest, environmental policies and regulations, evaluation of activities [16].

Mini garden uses tools and containers, one of which is Crop-box, which is a method of crop production by the process of modifying containers (recycling) into a controlled environmental space using a hydroponic system for crop production. Crop-box can be used from container or container material and can be placed anywhere in a city or urban environment because the characteristics of its mobility and ability can be stacked high making room efficiency [17]. The mini garden was chosen in this study because it was designed as a simple technology that was used as a source of learning in the daily learning process at daycare. The stages of mini garden implementation: Planning, Determining the container, selecting of planting media, seeding, communal planting, maintenance (watering, fertilizing and thinning), harvesting[18].

This research is needed at the location in daycare with the aim that the research process is maximized, where gardening activities require different time with different target yields. And full-time stimulation at daycare with a total of 12 hours of service/day. Locations at 3 Daycare in Dandelion Daycare Plus, Jasmine Daycare, Tsabitah Daycare, and Sanaya, all of which are in Depok City, have been observed in research conducted by Daycare that has supported gardening activities, and also helped children aged 5-6 years. The daycare center chosen in this study has a mini garden activity that is collaborated with parents for a program to improve and optimize children's growth and development abilities. But it has not yet integrated the mini garden activities into the curriculum program design. The reason is the teacher cannot arrange an integrated curriculum and support the overall ability of children including the ability to self-regulate. Related to observing self-ability in children is very low, and also does not have a learning activity strategy to improve self-ability. Even gardening is limited to playing in the yard and there are no specific learning goals.

\section{METHOD}

This study uses a questionnaire from the development of assessment for self-regulation aimed at three aspects, namely attention regulation, emotion regulation, and behavior regulation as many as 16 indicators and is equipped with interviews with caregivers and parents, this study also uses documentation for stimulation activities self-regulation through mini garden activities at each stage for 30 children. The research uses an action research method. This action is conducted in the spiral form of each cycle trough systematic steps that actively include study participants using the Kemmis and Taggart model[19], includes four stages: (1) planning, (2) action, (3) observation, and (4) reflection. The research used in this research is action research using mixed research method that is qualitative and quantitative method. The qualitative method aims to examine the learning process to increase the ability of children self-regulation with mini garden activities. Meanwhile, the qualitative method aims to examine the result of the ability to self-regulation with mini garden activities. The overall achievement targets increase the ability of the self-regulation ability with mini garden activities has been reached for $84,3 \%$. This is seen based on the minimum completeness of each daycare academic score by $73 \%$ as a final result. Action research says if the child has increased the score of learning achievement at least $71 \%$, the children show their success. If the percentage obtained is less than $71 \%$ for the learning score, then the research will be continued in the next cycle that is cycle II. In the research procedure, this action will be, preobservation, planning, action, observation, and reflection. Pre observation, undertaken at this pre-observation are: 1) determining the place of study and the problem studied, 2) collect information about the learning with the activities of mini garden and about the ability of self-regulation. After the pre-observation is done, then the next step is to plan the activities to be implemented are: 1) determine the target of competence to be achieved. 2) Designing the mini garden activities used for each action or meeting at each cycle; 3 ) determining the activity steps for each meeting/action; 4) setting the location of activities and preparing the tools, materials, media used.

Implementation of the action in eight times of action (mini garden) in cycle I. The result and level of success of the child will be shown at cycle I. If the result and level of success have not reached the expected success then will be done in the cycle of cycle and the observations were made during the execution of actions on mini garden activities with observation guidelines that included indicators designed based on the focus of the study: the concentration of numeracy learning to be improved which included; at the time of observation, in addition to using observation sheets, and interview guides the researchers also used a tool in the form of cameras to be able to record or document the process of action activities is how the children do mini garden activities. Analyzing the results of actions performed to the child does reflection, whether the action is done there is a shortage, increase or even a decrease in the ability of self-regulation. Learning methods and learning strategies in the second cycle were added using variations of the use of posters about the rules in the mini garden as a tool for self-control exercises and using videos about the procedures and rules for planting, caring and harvesting that children regularly deliver.

To test the level of validity in this study used Product moment. And to know the reliability of research instruments used Cronbach Alpha. Data analysis is divided into two, is the analysis of qualitative and quantitative data. Qualitative data obtained from observations, interviews, documentation and reflection results are collected and sorted by type, then analyzed inductively, with data reduction, data display, and data verification. While the quantitative data from the assessment of the development of the concentration of comparative learning is processed statistically to test the hypothesis of action, that is by using the study of the proportion of values.

\section{RESULT AND DISCUSSION}

Observation of the results of actions undertaken during the implementation is necessary for conducting data analysis in quantitative and qualitative terms. Observations were made 
using: observation instruments. The types of instruments used are field notes, documentation and interviews. The improvement of self-regulation through the mini garden in a group of children 5-6 years old for 4 Daycare Centers, Depok City, West Java. een in the following graph:

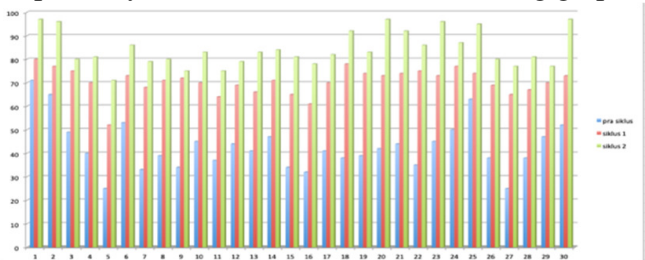

Fig. 1. Graph of Comparison of Pre-Action Score Result, Cycle I and Cycle II

\begin{tabular}{c|r|r|r|r|r|r|r|}
\hline Participant & Precycle & \multicolumn{1}{c|}{ Cycle 1 } & \multicolumn{1}{c|}{ Cycle 2 } & Participant & \multicolumn{1}{l|}{ Precycle } & \multicolumn{1}{c|}{ Cycle 1 } & \multicolumn{1}{c|}{ Cycle 2 } \\
\hline 1 & 71 & 80 & 97 & 16 & 32 & 61 & 78 \\
\hline 2 & 65 & 77 & 96 & 17 & 41 & 70 & 82 \\
\hline 3 & 49 & 75 & 80 & 18 & 38 & 78 & 92 \\
\hline 4 & 40 & 70 & 81 & 19 & 39 & 74 & 83 \\
\hline 5 & 25 & 52 & 71 & 20 & 42 & 73 & 97 \\
\hline 6 & 53 & 73 & 86 & 21 & 44 & 74 & 92 \\
\hline 7 & 33 & 68 & 79 & 22 & 35 & 75 & 86 \\
\hline 8 & 39 & 71 & 80 & 23 & 45 & 73 & 96 \\
\hline 9 & 34 & 72 & 75 & 24 & 50 & 77 & 87 \\
\hline 10 & 45 & 70 & 83 & 25 & 63 & 74 & 95 \\
\hline 11 & 37 & 64 & 75 & 26 & 38 & 69 & 80 \\
\hline 12 & 44 & 69 & 79 & 27 & 25 & 65 & 77 \\
\hline 13 & 41 & 66 & 83 & 28 & 38 & 67 & 81 \\
\hline 14 & 47 & 71 & 84 & 29 & 47 & 70 & 77 \\
\hline 15 & 34 & 65 & 81 & 30 & 52 & 73 & 97 \\
\hline
\end{tabular}

Fig. 2. Table of Comparison of Pre-Action Score Result, Cycle I and Cycle II

This research explains about increasing the ability of 30 children on the ability of self-regulation through mini garden activities. The table explains that there are 3 cycles, namely pre-cycle, first cycle and second cycle which shows an increase in children's abilities. From the graph above can be concluded that the self-regulation of children at 5-6 years old for 4 Daycare Centers in Depok has increased significantly and reached the number that has been targeted with 16 indicators. The results showed an increase in the overall percentage pre-cycle only $42,9 \%$, after the measures in the first cycle increased to $70,5 \%$, and for the second cycle raised to $84,3 \%$. The second result showed the highest percentage up to $97 \%$ from 30 children as the respondent and the lowest percentage was $73 \%$ from one of the respondents. This shows the effectiveness of the use of mini-gardens as an activity to improve self-regulation. There are 3 aspects of self-regulation on this research; attention regulation increased to $95 \%$ on the second cycle, before it was only $42,9 \%$ on pre-cycle, emotion regulation increased to $89,2 \%$ on the second cycle from $48 \%$ on the pre-cycle, and finally for the behavior regulation, increased to $80,2 \%$ on the second cycle before it only $41,3 \%$ on the pre-cycle. From each cycle shows the difference previously in the pre-cycle caregivers and educators in daycare only use the mini garden as a park without integrating it into the curriculum. In the second cycle there was an increase, based on observations educators and caregivers included mini garden activities to stimulate children's self-regulation abilities in the daily activity plan sheet in the curriculum and link them to learning themes, but the increase in children's self-regulation abilities was not as expected. But after the teacher designs and uses the rules on the poster for each stage of the mini garden activity, starting from the preparation stages of the planting media, seeding, maintenance to the harvest stage. every child is required to understand the rules made in the form of posters with pictures that are interesting for children and can be easily understood for children. It can be concluded that the ability of self-regulation in children can not only be increased through mini garden activities that are integrated with the curriculum but aspects of the ability of self-regulation namely, three aspects, namely: attention regulation, emotion regulation, and behavior regulation can be optimized by equipping mini garden activities with regulations at each stage of gardening in a mini garden and integrating it into other activities and still using rules to control children's behavior
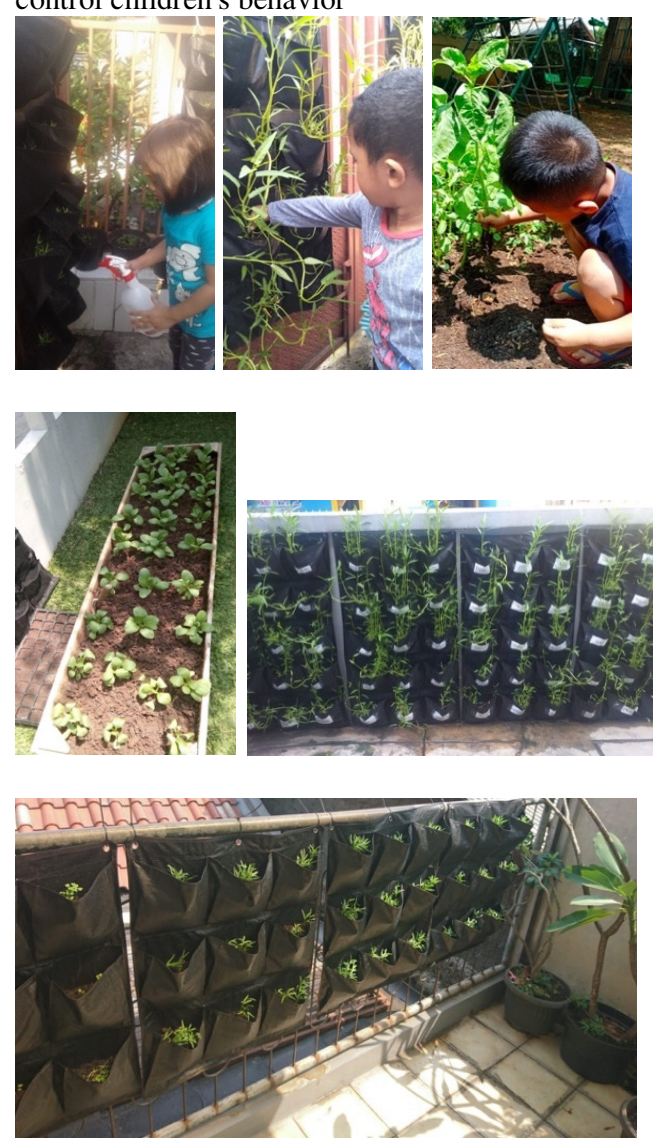

Pic. 1 Self - Regulation Through Mini Garden Activity

\section{CONCLUSION}

1. The result of the overall percentage of individual values in the pre-action, cycle cycle II and I have reached a total score of $73 \%$. While the average class has reached a total score of $84,3 \%$.

2. Mini Garden can increase the self-regulation ability that can be seen from the improvement of development achievement concentration in attention regulation, emotional regulation and behavior regulation at $42,9 \%$ 
in pre-cycle or pre-action and cycle I for $70,5 \%$ and $84,3 \%$ in cycle II.

The results show that self-regulation in children can be improved through mini gardens and mini gardens can improve children's self-regulation abilities by completing curriculum integration activities and using posters in the mini garden regulations. There is a significant increase of pre-action, cycle I and cycle II in every aspect of attention regulation, emotional regulation and behavior regulation for 16 indicators and 30 children in a group of children 5-6 years old at 3 Daycares in Depok that had chosen on this research. Teachers do the self-regulation ability by using the mini garden as part of smart pedagogy to solve the learning problem and adding the skill of self-regulation on children by using the appropriate technology and introduce them to Eco-friendly technology for their learning development. Teachers using smart pedagogy as the learning strategy with the steps: (1) create appropriate technology at daycare (2) provide the learning environment in daycare with rules, sign and picture/posters that can guide children to develop their self-regulation ability.

\section{REFERENCES}

[1] N. Bigras, L. Lemay, and L. Brunson, "Parental Stress and Daycare Attendance. Does Daycare Quality and Parental Satisfaction with Daycare Moderate the Relation Between Family Income and Stress Level among Parents of Four Years Old Children?," Procedia - Soc. Behav. Sci., vol. 55, no. October, pp. 894-901, 2012.

[2] L. M. Marulis, S. T. Baker, and D. Whitebread, "Integrating metacognition and executive function to enhance young children's perception of and agency in their learning," Early Child. Res. Q., vol. 50, no. 2018, pp. 4654, 2020.

[3] P. A. Graziano and K. Hart, "Beyond behavior modification: Benefits of social-emotional/selfregulation training for preschoolers with behavior problems," J. Sch. Psychol., vol. 58, pp. 91-111, 2016.

[4] T. R. Yuliasri, E. Nugraheny, and Atika, "Perbedaan Ibu Bekerja Dan Tidak Bekerja Terhadap Perkembangan Anak," J. Ilmu Kebidanan, vol. 05, pp. 119-125, 2015.

[5] S. Doebel and P. D. Zelazo, "A meta-analysis of the Dimensional Change Card Sort: Implications for developmental theories and the measurement of executive function in children," Dev. Rev., vol. 38, pp. 241-268, 2015.

[6] A. Zachariou and D. Whitebread,
"Developmental differences in young children's self-regulation," J. Appl. Dev. Psychol., vol. 62, no. May, pp. 282-293, 2019.

[7] J. Jakešová, P. Gavora, J. Kalenda, and S. Vávrová, "Czech Validation of the Selfregulation and Self-efficacy Questionnaires for Learning," Procedia - Soc. Behav. Sci., vol. 217, pp. 313-321, 2016.

[8] T. G. Yildiz, H. G. E. Kara, E. F. Tanribuyurdu, and M. Gönen, "Examining self-regulation skills according to teacher-child interaction quality," Egit. ve Bilim, vol. 39, no. 176, pp. 329-338, 2014.

[9] George S. Morrison, Dasar Dasar Pendidikan Anak Usia Dini (PAUD) Edisi Lima, 5th ed. Jakarta: PT.Indeks, 2012.

[10] M. W. D. Danuta Bukatko, Child Development: A Thematic Approach. Belmont: Cengage Learning, 2012.

[11] A. M. Uzun and S. Kilis, "Does persistent involvement in media and technology lead to lower academic performance? Evaluating media and technology use in relation to multitasking, self-regulation and academic performance," Comput. Human Behav., vol. 90, no. August 2018, pp. 196-203, 2019.

[12] P. Lan and S. Young, "International technology transfer examined at technology component level: A case study in China," Technovation, vol. 16, no. 6, pp. 277-286, 1996.

[13] T. Bruce, Early Childhood Practice: Froebel Today. 2012.

[14] Holly Farrell, RHS Miniature Garden Grower: Terrariums \& Other Tiny Gardens to Grow Indoors \& Out. Mitchell Beazley, 2016.

[15] I. E. Holttum, R. E., Gardening in the Tropics: The Definitive Guide for Gardeners. Marshall Cavendish Children's Books, 2011.

[16] K. G. Burt, P. Koch, and I. Contento, "Development of the GREEN (Garden Resources, Education, and Environment Nexus) Tool: An Evidence-Based Model for School Garden Integration," J. Acad. Nutr. Diet., vol. 117, no. 10, pp. 1517-1527.e4, 2017.

[17] J. Houtman, "Design and plan of a modified hydroponic shipping container for research," 2016. 
[18] T. Q. D. R.H. Paeru, Panduan praktis bertanam sayuran di Pekarangan. Penebar Swadaya, 2015.

[19] J. S. Mathhew B.Miles, A.Micahel Huberman, Qualitative Data Analysis A Methods

Sourcebook Edition 3. SAGE, 1995. 